\title{
Recent developments in thoracic endovascular aortic repair for chronic type B dissection
}

\author{
Shinichi Fukuhara ${ }^{1}$, Lise Tchouta ${ }^{1}$, Yujiro Yokoyama ${ }^{1}$, Rudra Pampati ${ }^{2}$, Minhaj S. Khaja ${ }^{2,3}$ \\ ${ }^{1}$ Department of Cardiac Surgery, University of Michigan, Ann Arbor, MI, USA; ${ }^{2}$ Department of Radiology, University of Michigan, Ann Arbor, MI, \\ USA; ${ }^{3}$ Department of Radiology, University of Virginia, Charlottesville, VA, USA \\ Contributions: (I) Conception and design: S Fukuhara, MS Khaja; (II) Administrative support: S Fukuhara; (III) Provision of study materials or \\ patients: S Fukuhara, L Tchouta; (IV) Collection and assembly of data: L Tchouta; (V) Data analysis and interpretation: L Tchouta, Y Yokoyama, S \\ Fukuhara; (VI) Manuscript writing: All authors; (VII) Final approval of manuscript: All authors. \\ Correspondence to: Shinichi Fukuhara, MD. Department of Cardiac Surgery, University of Michigan, 1500 E. Medical Center Drive, Ann Arbor, MI \\ 48109, USA. Email: fukuhara@med.umich.edu.
}

\begin{abstract}
The most common indication for the management of chronic type B aortic dissection (cTBAD) is aneurysmal dilatation of the dissected segment which has been traditionally managed via open repair for patients who were optimal surgical candidates. With the rise in popularity of endovascular therapies, thoracic endovascular aortic repair (TEVAR) is increasingly offered to patients with cTBAD. Although TEVAR is the standard of care in acute complicated type B dissections, its role, technical feasibility and outcomes in cTBAD remain controversial. The reasons for such controversy are largely due to the presence of a thick dissection septum, the lack of suitable landing zones and the persistent false lumen flow preventing positive aortic remodeling in the chronic aortic pathology. Nevertheless, there is mounting evidence supporting that TEVAR is a safe and successful therapy in patients for whom an open approach presents significant morbidity and mortality. The present review describes the technical considerations in catheter-based treatment approaches and respective outcomes. We also will examine the large armamentarium of techniques that have made TEVAR a reliable option in cTBAD.
\end{abstract}

Keywords: Chronic type B aortic dissection (cTBAD); degenerative aortic aneurysm; thoracic endovascular aortic repair (TEVAR); aortic remodeling

Received: 02 March 2020; Accepted: 22 May 2020; Published: 20 October 2021.

doi: 10.21037 /jovs-20-72

View this article at: http://dx.doi.org/10.21037/jovs-20-72

\section{Introduction}

Aortic dissection is part of a cluster of diseases known as aortic syndrome that also includes intramural hematoma, symptomatic aortic penetrating ulcer, and thoracic aortic rupture with an estimated annual incidence of 3 cases per 100,000 (1). Improvements in medical therapies have led to more patients with acute DeBakey type I aortic dissection and acute type $B$ dissection surviving and developing chronic type B aortic dissection (cTBAD). Generally, the accepted nomenclature for chronic disease is dissection older than 3 months. However, a new classification system based on data from the
International Registry of Acute Aortic Dissection (IRAD) proposed chronic dissection as older than 30 days (2). For those patients, the risk of complications including aneurysmal degeneration of the dissected segment, rupture, neurological signs, malperfusion, hypotension/shock, acute renal failure, or propagation of dissection has been reported with variable incidence and resultant need for an intervention (3-7). Approximately $20-40 \%$ of patients with acute uncomplicated TBAD will eventually require surgical intervention owing to complications from cTBAD. The most common of those complications is aneurysmal degeneration of the false lumen due to persistent inflow of blood and pressurization $(8,9)$. Another subset of 
patients with residual type B dissection, originally treated for proximal DeBakey type I dissection, will undergo late distal aortic interventions (6-15\%) secondary to persistent enlargement of the residually dissected distal aorta at the rate of 1-7 mm/year (10-13). The strategy for acute complicated TBAD has shifted from open surgical repair to thoracic endovascular aortic repair (TEVAR) in the past decade given the reduced procedural morbidity and mortality when compared to open interventions $(14,15)$. However, the optimal treatment for cTBAD with aortic adverse events necessitating interventions remains debated.

The primary goal of treatment for TBAD whether acute or chronic is to exclude the primary tear, discontinue blood entry into the false lumen and thus prevent the extension of dissection/aneurysm formation and eventually promote false lumen thrombosis and positive aortic remodeling. Consequently, the presence of a thickened intimal flap is a distinct limiting factor of TEVAR for cTBAD leading to a slow adoption of this technology. This is largely due to the theoretically sparse remodeling capacity of the aortic tissue compared to earlier stages of dissection as the intimal flap becomes increasingly thickened and rigid and less amenable to reverse aortic remodeling (16). Additionally, the presence of a thickened intimal flap may cause procedural complications including stent graft-induced new entry (SINE), de novo distal aortic dissection, occlusion of supraaortic and/or visceral vessels, intimal intussusception and retrograde aortic dissection following TEVAR. Although complete thrombosis of the false lumen and positive aortic remodeling appear relatively more achievable in the early phase of the disease (17), the results of TEVAR strategy for cTBAD have been mixed. Despite the concerns presented above, there are multiple published data on the successful use of TEVAR in cTBAD with documented reverse remodeling, depressurization of the false lumen, and thrombosis. We must balance these reports against those with treatment failures which argues for a patient selection algorithm for those with anatomic considerations that are best suited for endovascular therapies. Therefore, there has been a clear unmet need to achieve more satisfactory outcomes with TEVAR in cTBAD.

\section{Acute phase: optimal medical management versus early TEVAR}

Traditionally, optimal medical therapy (OMT) is reserved for acute uncomplicated dissection and mainly aims to reduce the force of left ventricular ejection which can contribute to the increased shear forces on an already compromised aortic wall. The first guidelines on medical therapies were officially published by the European Society of Cardiology and included blood pressure control, decreasing $\mathrm{dp} / \mathrm{dt}$, and decreasing aortic shear stress $(18,19)$. However, OMT alone is associated with high incidence of late aortic complications. These trends were first reported in the 1980s by DeBakey et al. and in the 1990s by Juvonen et al. who noted a rate of aneurysmal degeneration up to $40 \%$ in their respective cohorts among those who received OMT only (20,21). More recent data corroborate that those patients only treated medically are at high risk for aneurysmal degeneration and associated cumulative mortality up to $30 \%$ at 5 years $(7,16,22,23)$.

The effectiveness of TEVAR for uncomplicated TBAD in the early phase has been studied. The INvestigation of STEnt Grafts in Aortic Dissection (INSTEAD) trial demonstrated that $91 \%$ of patients with TBAD who underwent TEVAR at a median of 82 days following acute dissection achieved successful aortic remodeling compared to $19.4 \%$ of medically treated patients at 2 years (24). Subsequently, INSTEAD XL trial showed decreased allcause mortality in the TEVAR group compared to OMT (11.1\% TEVAR vs. $19.3 \%$ OMT, $\mathrm{P}=0.13$ ) and significantly lower aorta-specific mortality (6.9\% TEVAR vs. $19.3 \%$ OMT, $\mathrm{P}=0.04$ ) at 5 years (25). However, Nakamura et al. reported that OMT for octogenarians with uncomplicated TBAD had excellent outcomes (their 1-, 2-, and 5-year freedom from aorta-related death rates were 97, 97, and $97 \%$, respectively) (26). Based on these findings, it can be concluded that optimal treatment for uncomplicated TBAD should be individualized based on the anatomic suitability for TEVAR and patient medical risk profile. Furthermore, among those treated medically, physicians must maintain a low threshold for intervention in specific circumstances. Schwartz et al. established predictors of late aortic intervention that included entry tear $>10 \mathrm{~mm}$ [odds ratio (OR), 2.1; 95\% confidence interval (CI), 1.5-3.8; $\mathrm{P}=0.03$ ], total aortic diameter $>40 \mathrm{~mm}$ at presentation $(\mathrm{OR}, 2.2 ; 95 \%$ CI, 1.8-4.3; $\mathrm{P}=0.02)$, false lumen diameter $>20 \mathrm{~mm}(\mathrm{OR}$, 1.8; 95\% CI, 1.3-4.7; $\mathrm{P}=0.03$ ), and increase in total aortic diameter $>5 \mathrm{~mm}$ between serial imaging studies (OR, 2.3; $95 \% \mathrm{CI}, 1.3-3.5 ; \mathrm{P}=0.02)(27)$.

\section{TEVAR versus open surgical repair for aneurysmal degeneration}

Open repair for cTBAD associated with aneurysmal 
degeneration has been performed as the standard therapy. In chronic dissection, aortic aneurysmal degeneration with a diameter larger than $5.5 \mathrm{~cm}$ or a rapid expansion of the aortic diameter exceeding $0.5 \mathrm{~cm}$ in 6 months or saccular aneurysm protruding $\geq 2 \mathrm{~cm}$ beyond the aortic wall or increased diameter of the false lumen with a collapsed true lumen or symptoms caused by the aortic pathology are indications for surgical treatment $(8,28)$. However, open repair may be associated with relatively high mortality and devastating morbidity including spinal cord injury (SCI). The recent development of endovascular treatment is fueling a debate over the optimal treatment in this setting (29). Boufi et al. conducted a meta-analysis comparing outcomes of TEVAR and open repair for TBAD. They demonstrated lower early mortality, stroke and SCI for TEVAR, but higher reintervention rate and similar midterm survival (30).

Another meta-analysis assessed the early- and midterm outcomes of TEVAR, which reported $7.0 \%$ overall in-hospital mortality, $4.2 \%$ stroke, $3.3 \%$ SCI, $8.9 \%$ midterm mortality, and $12.5 \%$ secondary intervention rate (31). In response, Tanaka et al. reported the outcome of 427 patients with anatomy amenable to TEVAR who underwent open repair (32). Thirty-day mortality was $8.4 \%$, and the rate of stroke and SCI was $4.0 \%$ and $5.2 \%$, respectively. They also described previous descending/ thoracoabdominal aortic repair and chronic obstructive pulmonary disease (COPD) as associated with 30-day mortality. Patients without all 3 risk factors had a 30-day mortality rate of $2.6 \%$. Therefore, they concluded open repair is still a good approach for low-risk patients with cTBAD in experienced centers. Further investigation comparing long-term outcomes of TEVAR and open approach is required to determine the optimal treatment for cTBAD with aneurysmal degeneration.

\section{Complications related to TEVAR}

TEVAR is related to several detrimental complications including SCI and stroke (30,31). Additionally, SINE and retrograde aortic dissection are especially problematic, although both may occur regardless of the chronicity of the aortic dissection. Huang et al. conducted an observational cohort study including 65 patients with cTBAD who underwent TEVAR (33). They reported 18 patients (27.7\%) developed SINE, which was related to worse aortic remodeling compared to patients without SINE. A meta-analysis including 17 studies and 3962 patients who underwent TEVAR for
TBAD was conducted to assess the risk factors for distal SINE. They reported distal SINE occurred in 10.1\% and both the chronicity of TBAD and excess distal oversizing ratio were independent risk factors (34).

Retrograde type A dissection is another complication of TEVAR with a mortality rate of $37.1 \%$, although its incidence is relatively low $(2.5-3.9 \%)(31,35)$. Proximal landing zone diameter $>40 \mathrm{~mm}$ has been associated with increased risk ( $18 \%$ vs. $2 \%, \mathrm{P}=0.02)$ (36).

Because risk factors for complications or mortality following TEVAR have been well documented, a validated scoring system called Assessment of Thoracic Endografting Operative Mortality (ATOM) was developed by Kilic et al. to provide preoperative mortality risk stratification (37). The ATOM scoring system is a 30 -point risk score that incorporates 10 risk factors including: age $\geq 70$ years ( 2 points); body mass index $<30 \mathrm{~kg} / \mathrm{m}^{2}$ (3 points); COPD ( 2 points); functional assistance ( $0-4$ points); blood urea nitrogen $>25 \mathrm{mg} / \mathrm{dL}$ (3 points); white blood cell count $>12,000$ cells/ $\mu \mathrm{L}$ ( 2 points); emergency operation ( 3 points); left subclavian artery coverage (2 points); thoracoabdominal extension ( 2 points); mesenteric debranching (7 points). In their validation model, the ATOM scoring system predicted mortality for low (ATOM <5), moderate (ATOM 5 to 9), and high risk (ATOM $\geq 10)$ patients to be $1.3 \%, 6.6 \%$ and $24 \%(\mathrm{P}<0.001)$, respectively (37).

\section{Aortic remodeling}

Chronic TBAD resulted in poor aortic remodeling after TEVAR compared to acute TBAD. Conway et al. assessed the effectiveness of TEVAR for chronic TBAD using the Vascular Quality Initiative database (38). They included 125 patients and reported median change in sac diameter was $-0.2 \mathrm{~cm}$, sac shrinkage of $>0.5 \mathrm{~cm}$ was noted in 12 patients $(27.9 \%)$, and sac growth $>0.5 \mathrm{~cm}$ was observed in four $(9.3 \%)$ patients. Sultan et al. reviewed 48 patients who underwent TEVAR and reported that increasing number of visceral vessels off the false lumen, maximum preoperative aortic size and location of the primary tear on the greater curve were associated with poorer remodeling (39).

\section{Proposed techniques in TEVAR for cTBAD}

\section{Candy-plug}

In cTBAD, coverage of the proximal entry alone with TEVAR achieves complete false lumen thrombosis in 
only about $40 \%$ owing to a fibrotic dissection flap (40). Additionally, false lumen perfusion via retrograde flow arising from distal entry tears or branches off of the false lumen is not effectively protected by endografts. For those reasons, several techniques have been reported to facilitate false lumen thrombosis and aortic remodeling. The candyplug technique was first described in 2013 by Kölbel et al. (41). This is a custom-made endograft in the shape of a candy with distal diameters up to $50 \mathrm{~mm}$ and tapered in the middle down to $16 \mathrm{~mm}$. The plug is deployed into the false lumen to prevent backflow. The drawback of this technique is that this is not an off-the-shelf device and requires time to be custom-made.

\section{Coil embolization}

This adjunct to TEVAR exclusively targets the false lumen to induce thrombosis and aortic remodeling in cTBAD. The false lumen is cannulated through distal re-entry tears to deliver coils or Amplatzer vascular plugs in case of large false lumen. This approach is often utilized as a bailout after treatment failure of TEVAR or other adjunctive therapies. Pellenc et al. retrospectively analyzed data on 27 patients who underwent TEVAR for cTBAD with persistent false lumen perfusion or residual chronic type A dissection with coil embolization done as an adjunct during the index intervention or afterwards. They achieved complete false lumen thrombosis in 22 patients (81.5\%) (42). Five patients $(18.5 \%)$ required repeated embolization and one case of SCI was reported. Patients were followed for $20 \pm 10$ months with computed tomography (CT) angiography and maximum thoracic aortic diameter significantly decreased from $63 \mathrm{~mm}$ to $54 \pm 10 \mathrm{~mm}(\mathrm{P}<0.001)(42)$. Longer followup is necessary to confirm these successes and encourage the adoption of coil embolization as adjunct to TEVAR or as rescue therapy. Additionally, the cost related to this therapy is not negligible.

\section{Stent-assisted balloon-induced intimal disruption and relamination (STABILISE) concept}

Standard endovascular therapies for acute TBAD have focused on coverage of the proximal tear but studies had shown that there is incomplete remodeling of the distal dissected aorta. A meta-analysis of more than 600 patients with TBAD treated with endovascular stentgrafts placement showed that it failed to abolish the false lumen in about $25 \%$ of patients with persistent dilatation of the distal aorta (43). The Stage Total Aortic and Branch Vessel Endovascular (STABLE) reconstruction technique addressed this blind spot in TEVAR by combining proximal endografting with distal bare-metal stenting (44). Midterms data on the STABLE technique showed improved aortic remodeling and no evidence of false lumen perfusion in $23 \%$ of patients who were followed for a mean duration of 32 months (45). Moreover, when compared to stentgrafts only, those who received the STABLE repair had fewer rates of late distal aortic re-intervention ( $0 \%$ vs. $19 \%$, $\mathrm{P}=0.01)$ (46). It should be noted that this cohort included both type A and type B dissections.

Despite improved remodeling with the STABLE repair, $76 \%$ of patients still had some degree of false lumen perfusion which has led to a paradigm shift to breaking the dissection flap to create a common channel. The Stent-Assisted Balloon-Induced Intimal Disruption and Relamination in Aortic Dissection Repair (STABILISE) technique utilizes the stent-graft plus distal dissection stent seen in the STABLE repair with the addition of a balloon to disrupt the distal intimal flap and rebuild a common channel with the dissection stent (47). This technique was first described in 2014 and given its fairly recent introduction, limited long-term data on large population is available. Short-term data however have provided satisfactory results over its ability to completely exclude the false lumen without risking the integrity of the aorta with intimal flap rupture. In a small cohort of 10 patients with acute TBAD followed over a mean period of 7.2 months with CT angiogram, the false lumen had been completely excluded in all but one case where it was perfused from intercostal arteries (48). In these cohorts of exclusively acute TBAD cases, no rupture was noted but ballooning the aorta, particularly the distal aorta segment close to the uncovered portion, presents a serious risk of rupture. However, this concept has been adapted to chronic aorta pathology and stent graft-assisted dissection flap fracture with aorta balloon to create distal landing zones has been performed at experienced aorta centers including ours.

\section{Cheese wire fenestration}

In cTBAD, the presence of thickened intimal flap restricts the full expansion of the stent-graft in TEVAR resulting in persistent false lumen flow. With cheese wire fenestration, using a seesawing motion with a guidewire through an aortic septal fenestration (which may be pre-existing or intentionally created), an aortic septotomy is extended to 

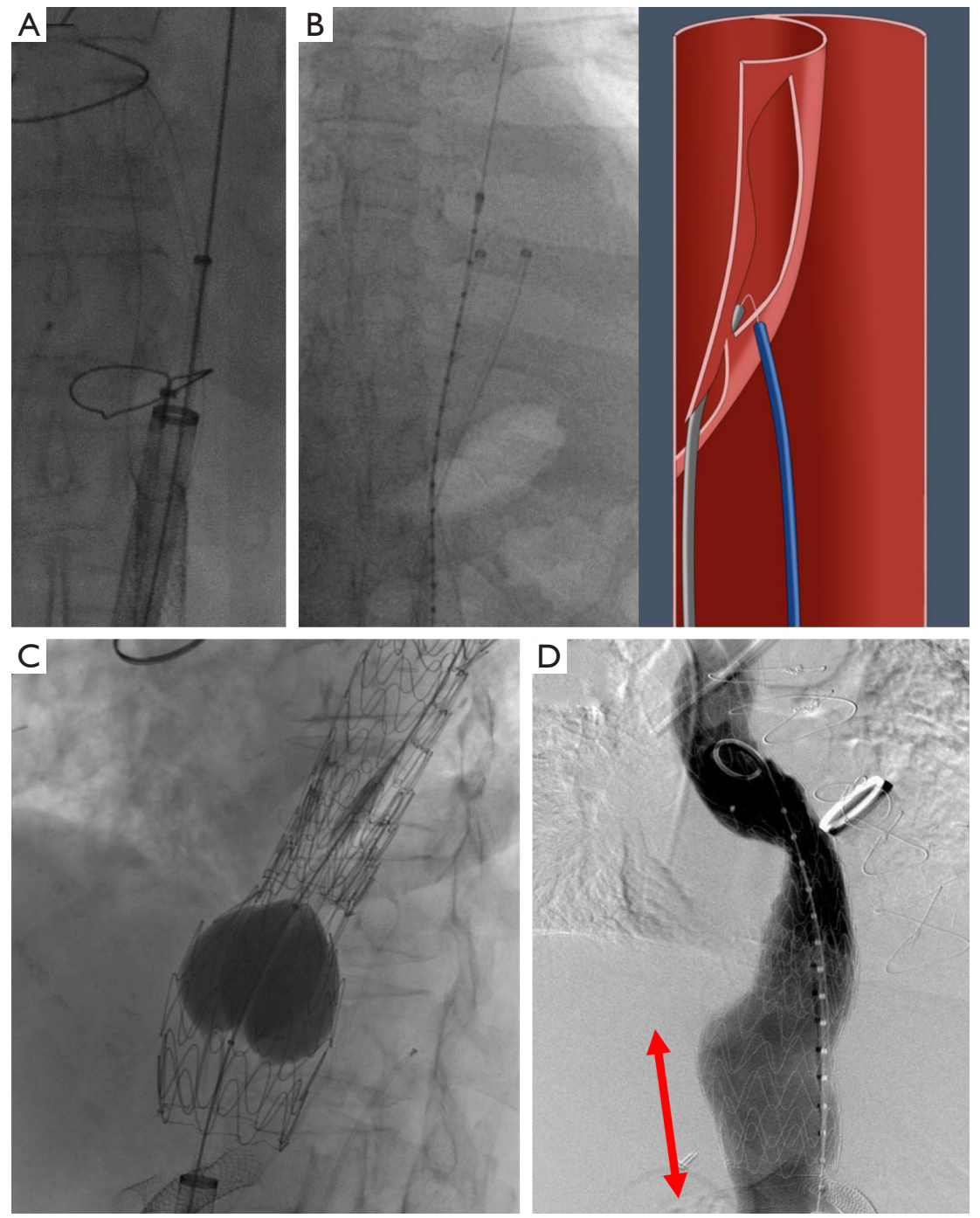

Figure 1 Basic steps for the cheese wire technique to create a distal uniluminal landing zone. (A) A 62-year-old female with residual type B dissection with degenerative descending aortic aneurysm. BRK-1 transseptal needle puncture followed by guidewire insertion from the true to the false lumen using $25 \mathrm{~mm}$ loop snare. (B) The established guidewire loop from the true and false lumen drawn together from the same femoral sheath. Other than the contacting portion to the aortic septum, the remainder of the guidewire was protected by 6-Fr catheter on both true and false lumen sides. The pre-existing dissection flap was extended caudally by the retraction of the guidewire and the fenestration was extended distally in order to facilitate a common lumen and distal landing zone creation. (C) Balloon aortoplasty following aortic device insertion. (D) Completion aortography with no evidence of endoleak. Red double arrow represents newly created common aortic lumen.

recreate a common aortic channel (Figure 1). Restoring a uniluminal aorta is also paramount when visceral aortic branches are perfused from the false lumen. This approach mandates balloon aortoplasty after the aortic device placement in order to fully expand the endograft (Figure 1C). In a case series, Iwakoshi et al. described the technique by creating a fenestration into the flap using a curved transjugular intrahepatic portosystemic shunt (TIPS) cannula and a snare over guidewire to pull the catheter initially inserted in the FL. This set-up established a through-and-through access from each femoral artery across the intimal flap. The authors argue that this technique of septotomy is safer with decreased risk of rupture in chronic cases compared to balloon angioplasty 
rupture of the dissection septum (49). In our approach, we typically use a BRK-1 (Abbott, St. Paul, MN) transseptal needle for the purpose of septal creation. Data available on the effectiveness of cheese wire fenestration is limited to case series with two to three patients including cases of chronic abdominal dissections (50-52). No large population data is currently available to offer comparisons to stand-alone TEVAR because of the novelty of this technique. For the same reason, follow-up data is reported up to 1 year only.

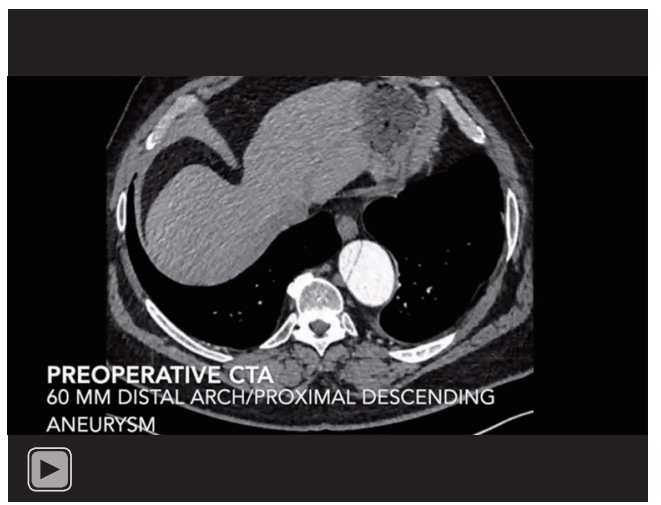

Video 1 Basic steps for the laser-assisted aortic dissection septotomy.

\section{Laser-assisted aortic dissection septotomy (Video 1)}

Despite various options available for the purpose of creating a common aortic lumen and distal landing zones, each technique has specific drawbacks and is not suitable for all cTBAD pathologies. We recently introduced the laser technology into this field (53). The laser-assisted longitudinal fenestration of the dissection flap involves longitudinally created $2.0-2.5 \mathrm{~mm}$ laser fenestrations on the dissection flap, which are immediately balloon-dilated using 16-22 mm balloons (ATLAS PTA Dilatation catheter; Bard Vascular Inc., Tempe, AZ). The positioning of the laser catheter (TurboElite OTW (Spectranetics, Colorado Springs, CO) is well-visualized by intravascular ultrasound (IVUS) under fluoroscopic guidance. The laser catheter is perpendicularly positioned using a $6.5 \mathrm{Fr}$ TourGuide steerable sheath (Medtronic, Santa Rosa, CA) (Figure 2A). This technique is applicable to a wide range of cTBAD pathologies, regardless of the thickness, chronicity, or location in the aorta, except for severely tortuous aorta where IVUS visualization with the laser catheter positioning is very challenging. Importantly, the size of fenestration created by laser with immediate balloon dilatation is much larger than the labeled balloon size, as the small true lumen in the setting of cTBAD makes the $4 \mathrm{~cm}$ length
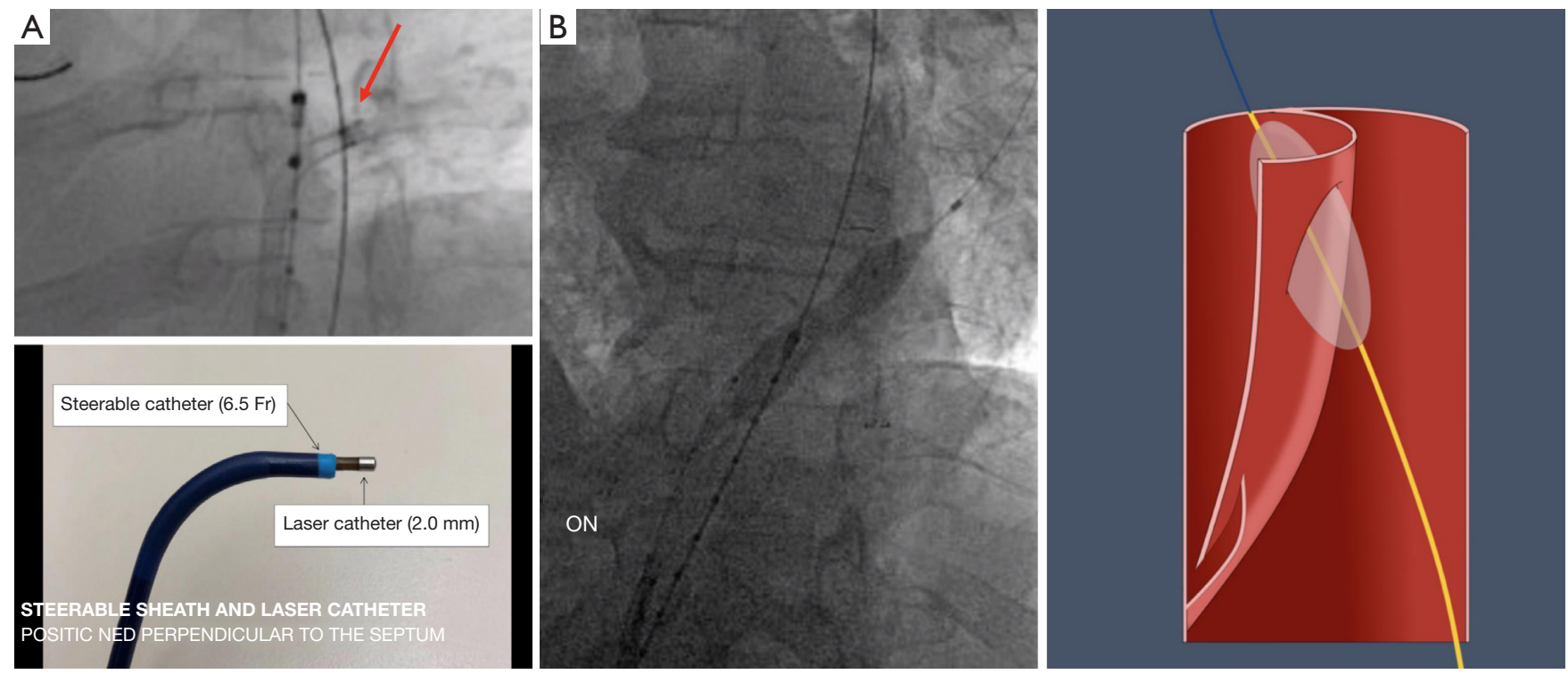

Figure 2 Basic steps for the laser-assisted aortic dissection septotomy. (A) Steerable sheath and laser catheter (red arrow) positioned perpendicularly to the septum under intravascular ultrasound and fluoroscopic guidance. (B) Laser fenestration was accessed with an 0.018 " guidewire and balloon dilated. Similar steps were repeated longitudinally to create $6-10 \mathrm{~cm}$ aortic septotomy. 

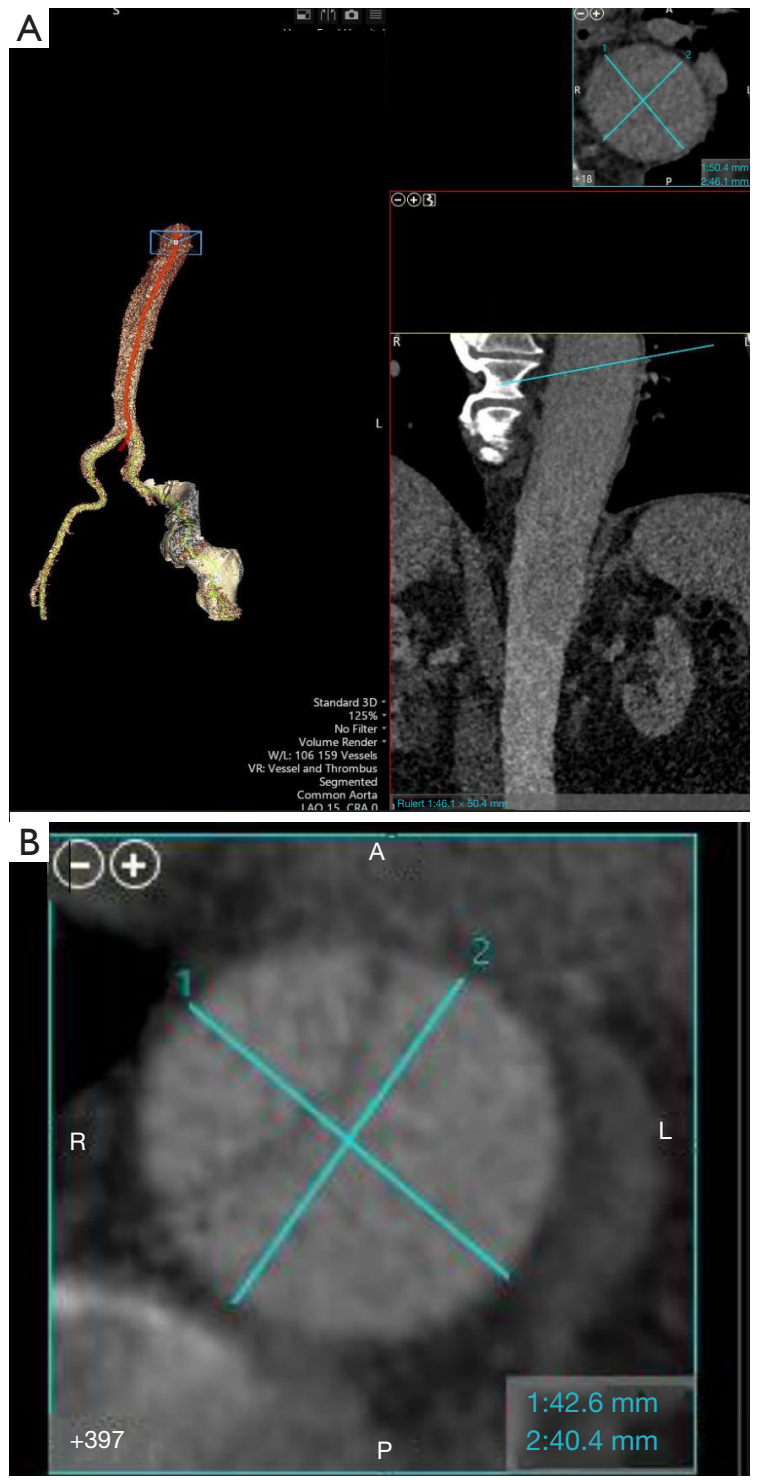

Figure 3 Computed tomography-based aorta sizing using the Vitrea workstation. (A) Example of centerline aorta sizing. (B) Measurement of total lumen aorta diameter rather than true lumen diameter. Mean of the long- and short-axis diameter is used for elliptical shape aorta sizing.

balloon obliquely positioned (Figure $2 B$ ). As a result, 2-3 fenestrations create fairly long longitudinal fenestrations totaling 5-8 $\mathrm{cm}$ in length. Once $2-3$ balloon-dilated longitudinal laser fenestrations are created, the dissection flap easily splits at $6-10 \mathrm{~cm}$ distance and the endograft typically spontaneously expands to its entire aorta diameter even without aortic ballooning. This laser fenestration is a more controlled form of aortic dissection flap septotomy maneuver than other techniques in this procedure category, allowing for accurate creation of a robust common aortic lumen at the intended location. This unique technique is particularly important in cases where the intimal flap is in close proximity to important branch vessels such as head, visceral, and renal arteries.

\section{Our TEVAR approach for cTBAD at the University of Michigan}

Our TEVAR approach for cTBAD does not remarkably differ from generally accepted practice. The number of patients with cTBAD undergoing TEVAR has been increasing in our aortic program and many of them are survivors following acute type A aortic dissection and proximal aortic repair. We have been using all commercially available endografts for this chronic aorta pathology. In addition to the CT-based aorta sizing, IVUS is always utilized and the intended proximal and distal landing zone IVUS measurements during systole are confirmed intraoperatively and correlated with the CT measurements. In terms of aorta sizing, precise centerline aorta sizing is mandatory (Figure 3). We routinely use Vitrea workstation (Vital Images, Minnetonka, MN). If common aorta lumen creation as the landing zone is planned, the total aorta diameter should be sized. The mean diameter of short and long axis is used when the aorta is of elliptical shape (Figure 3B). cTBAD is relatively more forgiving than acute TBAD regarding oversizing. However, the sizing should be individualized based on each aorta pathology and excessive oversizing should be avoided in order to avoid SINE or retrograde aortic dissection. As for creation of a robust distal landing zone in the presence of a thick dissection flap, we flexibly select and utilize the aforementioned technique to prepare for the device deployment.

\section{Selective devascularization concept}

We have previously established the relationship between covering the proximal entry tear and false lumen thrombosis but a novel concept has linked aortic branch vessels to false lumen thrombosis and aortic remodeling. Qin $e t$ al. identified risk factors for incomplete thrombosis of the false lumen including maximum diameter of the false lumen at the level of the abdominal aorta (OR 1.26, $\mathrm{P}<0.001$ ), re-entry tears (OR 30.6, $\mathrm{P}<0.001$ ), and the presence of branches that arose partially or totally from the false lumen $(\mathrm{OR} 10.05, \mathrm{P}<0.001)(54)$. These findings 
were corroborated by Dohle et al. in a cohort of 94 patients with acute DeBakey type 1 aortic dissection treated using frozen elephant trunk and followed with serial CT scan for at least 1 year. They showed that false lumen thrombosis negatively correlated with the presence of aortic branches arising from the false lumen and the presence of these branches was a predictor of negative remodeling (55). The presence of such branches thus represents a risk factor in treatment failure after TEVAR both in acute and chronic TBAD. Identification of the culprit false lumen branch(es) can be accomplished via 4D magnetic resonance imaging. Selective devascularization of these branches, possibly by means of stent from the aortic true lumen into the target vessels (for vital branches) or coil/vascular plug occlusion (for intercostal/lumbar branches) can theoretically limit the back flow into the false lumen and maximize positive aortic remodeling. This concept remains a topic for future investigation.

\section{Conclusions}

TBAD is a complex disease that leads to the development of aortic complications such as aneurysmal degeneration without surgical intervention. Early intervention with TEVAR is effective to achieve better aortic remodeling and may decrease overall mortality. The optimal treatment for cTBAD with aneurysmal degeneration is still under investigation. Open repair remains the standard strategy with acceptable morbidity particularly at an experienced center for select patients with minimal medical risk profile. TEVAR is related to better early perioperative outcomes compared to open repair but is associated to higher reintervention rates. Newly developed techniques in TEVAR to achieve complete false lumen thrombosis and better aortic remodeling have been emerging, demonstrating promising outcomes. Selecting a suitable technique or combination of techniques should be individualized based on the anatomy of the aortic pathology.

\section{Acknowledgments}

Funding: None.

\section{Footnote}

Provenance and Peer Review: This article was commissioned by the Guest Editors (Ibrahim Sultan and George Arnaoutakis) for the series "Advancement in the Surgical Treatment of
Aortic Dissection" published in Fournal of Visualized Surgery. The article has undergone external peer review.

Conflicts of Interest: All authors have completed the ICMJE uniform disclosure form (available at https:// jovs.amegroups.com/article/view/10.21037/jovs-20-72/ coif). The series "Advancement in the Surgical Treatment of Aortic Dissection" was commissioned by the editorial office without any funding or sponsorship. SF serves as a consultant for Terumo Aortic. The authors have no other conflicts of interest to declare.

Ethical Statement: The authors are accountable for all aspects of the work in ensuring that questions related to the accuracy or integrity of any part of the work are appropriately investigated and resolved. All procedures performed in this study were in accordance with the Helsinki Declaration (as revised in 2013). The manuscript is waived from patient informed consent according to the ethics committee or institutional review board.

Open Access Statement: This is an Open Access article distributed in accordance with the Creative Commons Attribution-NonCommercial-NoDerivs 4.0 International License (CC BY-NC-ND 4.0), which permits the noncommercial replication and distribution of the article with the strict proviso that no changes or edits are made and the original work is properly cited (including links to both the formal publication through the relevant DOI and the license). See: https://creativecommons.org/licenses/by-nc-nd/4.0/.

\section{References}

1. Tsai TT, Nienaber CA, Eagle KA. Acute Aortic Syndromes. Circulation 2005;112:3802-13.

2. Booher AM, Isselbacher EM, Nienaber CA, et al. The IRAD Classification System for Characterizing Survival after Aortic Dissection. Am J Med 2013;126:730.e19-730.e24.

3. Nauta FJ, Trimarchi S, Kamman AV, et al. Update in the management of type B aortic dissection. Vasc Med 2016;21:251-63.

4. Hiratzka LF, Bakris GL, Beckman JA, et al. 2010 ACCF/AHA/AATS/ACR/ASA/SCA/SCAI/SIR/STS/ SVM guidelines for the diagnosis and management of patients with Thoracic Aortic Disease: a report of the American College of Cardiology Foundation/American Heart Association Task Force on Practice Guidelines, American Association for Thoracic Surgery, American 
College of Radiology, American Stroke Association, Society of Cardiovascular Anesthesiologists, Society for Cardiovascular Angiography and Interventions, Society of Interventional Radiology, Society of Thoracic Surgeons, and Society for Vascular Medicine. Circulation 2010;121:e266-369.

5. Hagan PG, Nienaber CA, Isselbacher EM, et al. The International Registry of Acute Aortic Dissection (IRAD): new insights into an old disease. JAMA 2000;283:897-903.

6. Szeto WY, McGarvey M, Pochettino A, et al. Results of a new surgical paradigm: endovascular repair for acute complicated type B aortic dissection. Ann Thorac Surg 2008;86:87-93; discussion 93-4.

7. Erbel R, Aboyans V, Boileau C, et al. 2014 ESC Guidelines on the diagnosis and treatment of aortic diseases:

Document covering acute and chronic aortic diseases of the thoracic and abdominal aorta of the adult. The Task Force for the Diagnosis and Treatment of Aortic Diseases of the European Society of Cardiology (ESC). Eur Heart J 2014;35:2873-926.

8. Parsa CJ, Schroder JN, Daneshmand MA, et al. Midterm results for endovascular repair of complicated acute and chronic type B aortic dissection. Ann Thorac Surg 2010;89:97-102; discussion 102-4.

9. Parsa CJ, Williams JB, Bhattacharya SD, et al. Midterm results with thoracic endovascular aortic repair for chronic type B aortic dissection with associated aneurysm. J Thorac Cardiovasc Surg 2011;141:322-7.

10. Rylski B, Milewski RK, Bavaria JE, et al. Long-term results of aggressive hemiarch replacement in 534 patients with type A aortic dissection. J Thorac Cardiovasc Surg 2014;148:2981-5.

11. Halstead JC, Meier M, Etz C, et al. The fate of the distal aorta after repair of acute type A aortic dissection. J Thorac Cardiovasc Surg 2007;133:127-35.

12. Rylski B, Beyersdorf F, Kari FA, et al. Acute type A aortic dissection extending beyond ascending aorta: Limited or extensive distal repair. J Thorac Cardiovasc Surg 2014;148:949-54.

13. Zierer A, Voeller RK, Hill KE, et al. Aortic Enlargement and Late Reoperation After Repair of Acute Type A Aortic Dissection. Ann Thorac Surg 2007;84:479-86; discussion 486-7.

14. Fattori R, Cao P, De Rango P, et al. Interdisciplinary expert consensus document on management of type $B$ aortic dissection. J Am Coll Cardiol 2013;61:1661-78.

15. Coady MA, Ikonomidis JS, Cheung AT, et al. Surgical management of descending thoracic aortic disease: open and endovascular approaches: a scientific statement from the American Heart Association. Circulation 2010;121:2780-804.

16. Svensson LG, Kouchoukos NT, Miller DC, et al. Expert consensus document on the treatment of descending thoracic aortic disease using endovascular stent-grafts. Ann Thorac Surg 2008;85:S1-41.

17. Nienaber CA, Kische S, Ince H, et al. Thoracic endovascular aneurysm repair for complicated type B aortic dissection. J Vasc Surg 2011;54:1529-33.

18. Erbel R, Alfonso F, Boileau C, et al. Diagnosis and management of aortic dissection Task Force on Aortic Dissection, European Society of Cardiology. Eur Heart J 2001;22:1642-81.

19. Suzuki T, Eagle KA, Bossone E, et al. Medical management in type B aortic dissection. Ann Cardiothorac Surg 2014;3:413-7.

20. DeBakey ME, McCollum CH, Crawford ES, et al. Dissection and dissecting aneurysms of the aorta: Twentyyear follow-up of five hundred twenty-seven patients treated surgically. Surgery 1982;92:1118-34.

21. Juvonen T, Ergin MA, Galla JD, et al. Risk factors for rupture of chronic type B dissections. J Thorac Cardiovasc Surg 1999;117:776-86.

22. Suzuki T, Mehta RH, Ince H, et al. Clinical profiles and outcomes of acute type $\mathrm{B}$ aortic dissection in the current era: lessons from the International Registry of Aortic Dissection (IRAD). Circulation 2003;108 Suppl 1:II312-317.

23. Suzuki T, Isselbacher EM, Nienaber CA, et al. Typeselective benefits of medications in treatment of acute aortic dissection. Am J Cardiol 2012;109:122-7.

24. Nienaber CA, Rousseau H, Eggebrecht H, et al. Randomized comparison of strategies for type $\mathrm{B}$ aortic dissection: the INvestigation of STEnt Grafts in Aortic Dissection (INSTEAD) trial. Circulation 2009;120:2519-28.

25. Nienaber CA, Kische S, Rousseau H, et al. Endovascular repair of type $\mathrm{B}$ aortic dissection: long-term results of the randomized investigation of stent grafts in aortic dissection trial. Circ Cardiovasc Interv 2013;6:407-16.

26. Nakamura K, Uchida T, Hamasaki A, et al. How should we treat uncomplicated subacute type $\mathrm{B}$ aortic dissection in octogenarians? J Cardiothorac Surg 2019;14:44.

27. Schwartz SI, Durham C, Clouse WD, et al. Predictors of late aortic intervention in patients with medically treated type B aortic dissection. J Vasc Surg 2018;67:78-84.

28. Andersen ND, Keenan JE, Ganapathi AM, et al. Current management and outcome of chronic type B aortic dissection: results with open and endovascular repair since 
the advent of thoracic endografting. Ann Cardiothorac Surg 2014;3:264-74.

29. Burke CR, Bavaria JE. The Role of Thoracic Endovascular Repair in Chronic Type B Aortic Dissection. Semin Thorac Cardiovasc Surg 2020;32:21-4.

30. Boufi M, Patterson BO, Loundou AD, et al. Endovascular Versus Open Repair for Chronic Type B Dissection Treatment: A Meta-Analysis. Ann Thorac Surg 2019;107:1559-70.

31. Li HL, Wu S, Chan YC, et al. Early and mid-term mortality and morbidity of contemporary international endovascular treatment for type B aortic dissection A systematic review and meta-analysis. Int J Cardiol 2020;301:56-61.

32. Tanaka A, Sandhu HK, Afifi RO, et al. Outcomes of open repairs of chronic distal aortic dissection anatomically amenable to endovascular repairs. J Thorac Cardiovasc Surg 2019. doi:10.1016/j.jtcvs.2019.09.083.

33. Huang CY, Hsu HL, Chen PL, et al. The Impact of Distal Stent Graft-Induced New Entry on Aortic Remodeling of Chronic Type B Dissection. Ann Thorac Surg 2018;105:785-93.

34. D'cruz RT, Syn N, Wee I, et al. Risk factors for distal stent graft-induced new entry in type B aortic dissections: Systematic review and meta-analysis. J Vasc Surg 2019;70:1682-93.e1.

35. Chen Y, Zhang S, Liu L, et al. Retrograde Type A Aortic Dissection After Thoracic Endovascular Aortic Repair: A Systematic Review and Meta-Analysis. J Am Heart Assoc 2017;6:e004649.

36. Tjaden BL, Sandhu H, Miller C, et al. Outcomes from the Gore Global Registry for Endovascular Aortic Treatment in patients undergoing thoracic endovascular aortic repair for type B dissection. J Vasc Surg 2018;68:1314-23.

37. Kilic A, Sultan IS, Arnaoutakis GJ, et al. Assessment of Thoracic Endografting Operative Mortality Risk Score: Development and Validation in 2,000 Patients. Ann Thorac Surg 2015;100:860-7.

38. Conway AM, Qato K, Mondry LR, et al. Outcomes of thoracic endovascular aortic repair for chronic aortic dissections. J Vasc Surg 2018;67:1345-52.

39. Sultan I, Siki MA, Bavaria JE, et al. Predicting Distal Aortic Remodeling After Endovascular Repair for Chronic DeBakey III Aortic Dissection. Ann Thorac Surg 2018;105:1691-6.

40. Kusagawa H, Shimono T, Ishida $M$, et al. Changes in false lumen after transluminal stent-graft placement in aortic dissections: six years' experience. Circulation
2005;111:2951-7.

41. Kölbel T, Lohrenz C, Kieback A, et al. Distal false lumen occlusion in aortic dissection with a homemade extra-large vascular plug: the candy-plug technique. J Endovasc Ther 2013;20:484-9.

42. Pellenc Q, Roussel A, De Blic R, et al. False lumen embolization in chronic aortic dissection promotes thoracic aortic remodeling at midterm follow-up. J Vasc Surg 2019;70:710-7.

43. Eggebrecht $H$, Nienaber CA, Neuhäuser $M$, et al. Endovascular stent-graft placement in aortic dissection: a meta-analysis. Eur Heart J 2006;27:489-98.

44. Mossop PJ, McLachlan CS, Amukotuwa SA, et al. Staged endovascular treatment for complicated type $\mathrm{B}$ aortic dissection. Nat Clin Pract Cardiovasc Med 2005;2:316-21.

45. Hofferberth SC, Foley PT, Newcomb AE, et al. Combined Proximal Endografting With Distal Bare-Metal Stenting for Management of Aortic Dissection. Ann Thorac Surg 2012;93:95-102.

46. Hofferberth SC, Newcomb AE, Yii MY, et al. Combined proximal stent grafting plus distal bare metal stenting for management of aortic dissection: Superior to standard endovascular repair? J Thorac Cardiovasc Surg 2012;144:956-62; discussion 962.

47. Hofferberth SC, Nixon IK, Boston RC, et al. StentAssisted Balloon-Induced Intimal Disruption and Relamination in Aortic Dissection Repair: The STABILISE concept. J Thorac Cardiovasc Surg 2014;147:1240-5.

48. Melissano G, Bertoglio L, Rinaldi E, et al. Satisfactory short-term outcomes of the STABILISE technique for type B aortic dissection. J Vasc Surg 2018;68:966-75.

49. Iwakoshi S, Watkins CA, Ogawa Y, et al. "Cheese Wire" Fenestration of Dissection Intimal Flap to Facilitate Thoracic Endovascular Aortic Repair in Chronic Dissection. J Vasc Interv Radiol 2020;31:150-4.e2.

50. Tashiro J, Baqai A, Goldstein LJ, et al. "Cheese wire" fenestration of a chronic aortic dissection flap for endovascular repair of a contained aneurysm rupture. $\mathrm{J}$ Vasc Surg 2014;60:497-9.

51. Barshes NR, Gravereaux EC, Semel M, et al. Endovascular longitudinal fenestration and stent graft placement for treatment of aneurysms developing after chronic type B aortic dissection. J Vasc Surg 2015;61:1366-9.

52. Gissler MC, Ogawa Y, Lee JT, et al. Percutaneous Septectomy in Chronic Dissection with Abdominal Aortic Aneurysm Creates Uniluminal Neck for EVAR. Cardiovasc Intervent Radiol 2017;40:1522-8. 
53. Fukuhara S, Williams D, Patel HJ, et al. Laser-Assisted Longitudinal Aortic Septotomy: Laser Bullet Technique. 100th American Association for Thoracic Surgery (AATS) Annual Meeting, 2020.

54. Qin YL, Deng G, Li TX, et al. Risk factors of incomplete thrombosis in the false lumen after endovascular treatment

doi: 10.21037/jovs-20-72

Cite this article as: Fukuhara S, Tchouta L, Yokoyama Y, Pampati R, Khaja MS. Recent developments in thoracic endovascular aortic repair for chronic type B dissection. J Vis Surg 2021;7:40. of extensive acute type B aortic dissection. J Vasc Surg 2012;56:1232-8.

55. Dohle DS, Jakob H, Schucht R, et al. The impact of entries and exits on false lumen thrombosis and aortic remodelling. Eur J Cardiothorac Surg 2017;52:508-15. 